\title{
Glycated Haemoglobin (HbA1c) Variations in Nondiabetics With Nutritional Anemia
}

\author{
Rakesh Pilla $^{1}$, Sujith Kumar Palleti ${ }^{2}$, Renuka Rayana ${ }^{3}$, Satish Reddy SKSS ${ }^{1}$, Aminah Abdul Razzack ${ }^{4}$, \\ Sruti Kalla ${ }^{1}$
}

1. Internal Medicine, Maharajah's Institute of Medical Sciences, Vizianagaram, IND 2. Internal Medicine, MNR Medical College \& Hospital, Sangareddy, IND 3. Internal Medicine, Andhra Medical College, Visakhapatnam, IND 4. Internal Medicine, Mallareddy Medical College For Women, Hyderabad, IND

Corresponding author: Rakesh Pilla, rakeshpillaa@gmail.com

\section{Abstract \\ Objectives:}

Diabetes is prevalent in the Indian population, to the extent that the diabetes burden matches that of nutritional anemia. We aimed to determine the effects of iron and vitamin B12 deficiency anemia on glycated haemoglobin (HbA1c) concentrations in individuals without diabetes.

\section{Material and methods:}

The study comprises 100 patients with iron deficiency anemia, 100 with vitamin B12 deficiency anemia, and 100 healthy volunteers as a control group. Each of the first two groups was subdivided into two groups depending on the severity of anemia based on Hb levels. We treated with iron replenishment in the iron deficiency group and B12 replenishment in the B12 deficiency group for three months. We noted HbA1c levels before and after the therapy. Data were entered into the SPSS package. For comparing pre and posttherapy levels, we used the Paired ' $t$ ' test.

\section{Results:}

The mean HbA1c before treatment were $6.1 \% \pm 0.23 \%$ and $5.5 \% \pm 0.24 \%$, and the values after treatment were $5.1 \% \pm 0.14 \%$ and $4.6 \% \pm 0.2 \%$ in severe iron deficiency anemia subgroup and mild to moderate subgroup, respectively. The mean HbA1c in the iron-deficiency anemia control group was $5.2 \% \pm 0.2 \%$. The mean HbA1c levels before treatment were $5.9 \% \pm 0.3 \%$ and $5.6 \% \pm 0.19 \%$, and after treatment were $5.0 \% \pm 0.15 \%$ and $4.9 \% \pm 0.16 \%$ in severe and mild to moderate B12 deficiency anemia, respectively. The mean HbA1c in the vitamin B12 deficiency anemia control group was $5.1 \% \pm 0.2 \%$.

\section{Conclusion:}

HbA1c in both types of anemia subjects showed a significant decrease with appropriate therapy. Physicians should consider rechecking patient haemoglobin values and correcting a patient's anemia before

Review began 10/05/2020 Review ended 11/12/2020 Published 11/13/2020

\section{() Copyright 2020}

Pilla et al. This is an open access article distributed under the terms of the Creative Commons Attribution License CC-BY 4.0., which permits unrestricted use, distribution, and reproduction in any medium, provided the original author and source are credited.
Categories: Endocrinology/Diabetes/Metabolism, Internal Medicine, Hematology Keywords: anemia, iron deficiency, b12 deficiency, hba1c

\section{Introduction}

Glycated haemoglobin (HbA1c) is defined as haemoglobin $(\mathrm{Hb})$ that is irreversibly glycated at one or both Nterminal valines of the beta chains and remains in the red blood cell (RBC) for the rest of its lifespan [1,2]. Therefore, HbA1c is used as a measure of a patient's glycemic status over the past three months [3]. HbA1c concentrations are not only altered by blood glucose levels [4], but they also vary significantly in a few diseases and pathological states, such as hypoproliferative anemia and hemoglobinopathies $[5,6]$.

Conditions that prolong the erythrocyte lifespan or conditions related to decreased RBC turnover will lead to prolonged exposure of the cell to glucose, resulting in higher HbA1c [7]. Similarly, states that reduce the lifespan of RBCs or conditions where RBC exposure to glucose is shortened (i.e., from an increase in RBC turnover) will result in reduced $\mathrm{HbA1c}$ concentrations. Iron deficiency anemia and vitamin B12 deficiency anemia fall into the former scenario.

Initially, we considered $\mathrm{HbA1c}$ as a marker for monitoring glycemic control. However, recently HbA1c has also been recommended as a diagnostic indicator of diabetes [5]. The American Diabetes Association (ADA) included $\mathrm{HbA1c}$ alone as a diagnostic tool for diabetes in 2010 [1], and we still consider $\mathrm{HbA1c}$ a reliable marker for diabetes control as per the 2018 ADA guidelines [8]. Factors altering HbA1c concentrations are $\mathrm{Hb}$ variants [9], hemolytic anemia, renal failure [10], hypothyroid [11], alcoholism, and hyperbilirubinemia. In 
this study, we aimed to look for HbA1c variations in nutritional anemia and their consideration with $\mathrm{HbA1c}$ as a diagnostic tool.

Our aims and objectives were to determine the effects of iron and vitamin B12 deficiency anemia on HbA1c in individuals without diabetes, to study HbA1c in anemia patients, and to study how variations in $\mathrm{HbA1c}$ may correlate to the degree of anemia.

\section{Materials And Methods}

This was a prospective follow-up study consisting of 300 subjects (100 iron-deficient patients, 100 B12deficient anemia patients, and 100 healthy controls). The study was performed at the Maharajah Institute of Medical Sciences from December 2017 to November 2019.

The ethical committee gave ethical clearance for the present study (MIMS/IEC - 11/2017). The 300 subjects were included after providing written and informed consent. History and physical examination data were thoroughly collected to rule out other causes of anemia, and investigations including $\mathrm{Hb}$ (\%) values, serum iron, serum ferritin, serum B12 values, fasting blood glucose (FBG) levels, and HbA1c concentrations were conducted.

Our study included iron and or B12 deficiency anemia patients aged 18 years to 70 years of either sex and willing to undergo required investigations. Our study excluded patients with hemolytic anemia and aplastic anemia, patients with diabetes mellitus, pregnant women, and patients with anemia of chronic diseases.

The study population was selected per our inclusion criteria, and the controls were picked to match the gender and age of the study groups. The study population of both iron deficiency anemia and vitamin B12 deficiency anemia were further divided into two groups depending on the degree of anemia. Group 1 included patients with severe anemia (i.e., $\mathrm{Hb}<8 \mathrm{~g} / \mathrm{dL}$ ). Group 2 consisted of patients with mild and moderate anemia (i.e., $\mathrm{Hb} 8$ to $11.9 \mathrm{~g} / \mathrm{dL}$ in women, $\mathrm{Hb} 8$ to $12.9 \mathrm{~g} / \mathrm{dL}$ in men per the World Health Organization 2011 guidelines [12]). Their $\mathrm{Hb} \%$, serum iron, ferritin, B12 values, and $\mathrm{HbA1c}$ were recorded, and they were treated with iron replenishment in the iron deficiency group and B12 replenishment in the B12 deficiency group for three months. The same investigations were repeated in follow-up visits until the anemia was corrected, and final values were recorded for our study. The change in HbAlc concerning the correction of each of these anemia types were recorded.

For statistical analysis, data were entered into SPSS for Windows, Version 16.0. (Chicago, SPSS Inc.). For comparing parameters before and after treatment, we used the paired t-test. We calculated mean $\mathrm{Hb}$ and mean HbA1c for each type of anemia. The standard deviation was calculated, and the p-value was obtained. A p-value $<.05$ was considered statistically significant.

\section{Results}

The mean age of patients with iron deficiency anemia was 38 years, whereas patients in the vitamin B12 deficiency anemia had a mean age of 45 years. The mean age of the control group patients was 40 years. The mean FBG levels in the iron-deficiency anemia group were $86 \pm 5.72 \mathrm{~g} / \mathrm{dL}$, the mean FBG in the vitamin B12 deficiency group was $90 \pm 3.12 \mathrm{~g} / \mathrm{dL}$, the mean FBG in the control group was $80 \pm 8.6 \mathrm{~g} / \mathrm{dL}$.

Regarding the correction of the underlying anemia, the mean $\mathrm{Hb}$ levels $(\mathrm{g} / \mathrm{dL})$ among the iron-deficiency anemia groups before and after treatment are presented in table 1 . Table 2 presents the mean $\mathrm{Hb}$ levels $(\mathrm{g} / \mathrm{dL})$ among vitamin B12 deficiency anemia groups before and after treatment.

\begin{tabular}{|c|c|c|c|}
\hline Iron deficiency anemia & Before treatment (mean $\mathrm{Hb} \pm \mathrm{SD}$ ) & After treatment (mean $\mathrm{Hb} \pm \mathrm{SD}$ ) & P-value \\
\hline Group 1 & $6.2 \pm 0.2$ & $12.3 \pm 0.13$ & $<.001$ \\
\hline Group 2 & $9.4 \pm 0.72$ & $13.5 \pm 0.28$ & $<.001$ \\
\hline \multicolumn{4}{|c|}{$\begin{array}{l}\text { TABLE 1: Mean haemoglobin levels }(\mathrm{g} / \mathrm{dL}) \text { in mild and moderate iron deficiency anemia groups } \\
\text { before and after treatment }\end{array}$} \\
\hline \multicolumn{4}{|c|}{ Abbreviations: Hb, hemoglobin; SD, standard deviation. } \\
\hline
\end{tabular}




\section{Cureus}

\begin{tabular}{|c|c|c|c|}
\hline Vitamin B12 deficiency anemia & Before treatment (mean $\mathrm{Hb} \pm \mathrm{SD}$ ) & After treatment (mean $\mathrm{Hb} \pm \mathrm{SD}$ ) & P-value \\
\hline Group 1 & $6.7 \pm 0.17$ & $12.6 \pm 0.18$ & $<.001$ \\
\hline Group 2 & $9.3 \pm 0.32$ & $13.2 \pm 0.14$ & $<.001$ \\
\hline
\end{tabular}

TABLE 2: Mean haemoglobin levels $(\mathrm{g} / \mathrm{dL})$ in mild and moderate vitamin B12 deficiency anemia groups before and after treatment

Abbreviations: $\mathrm{Hb}$, haemoglobin; SD, standard deviation.

For iron-deficiency anemia patients, those in Group 1 showed a significant reduction in mean HbA1c from $6.1 \% \pm 0.23 \%$ to $5.1 \% \pm 0.14 \%(\mathrm{P}<.01)$. Group 2 iron-deficiency patients showed a significant reduction of mean $\mathrm{HbA} 1 \mathrm{c}$ from $5.5 \pm 0.24 \%$ to $4.6 \pm 0.2 \%(\mathrm{P}<.001$; Table 3$)$.

\begin{tabular}{|l|l|l|}
\hline Iron deficiency anemia & Before treatment (mean HbA1c \pm SD) & After treatment (mean HbA1c \pm SD) \\
\hline Group 1 & $6.1 \pm 0.23$ & $5.1 \pm 0.14$ \\
\hline Group 2 & $5.5 \pm 0.24$ & $4.6 \pm 0.2$ \\
\hline
\end{tabular}

TABLE 3: Mean HbA1c concentrations in mild and moderate iron-deficiency anemia groups before and after treatment

Abbreviations: HbA1c, glycated haemoglobin; SD, standard deviation.

For vitamin B12-deficiency anemia patients in Group 1, the initial mean $\mathrm{HbA} 1 \mathrm{c}$ was $5.9 \% \pm 0.3 \%$, and it decreased significantly to $5.0 \% \pm 0.15 \%$ with treatment $(\mathrm{P}<.001)$. Group $2 \mathrm{~B} 12$-deficiency patients also showed a significant decrease in HbA1c with the treatment of anemia. The initial mean HbA1c in Group 2 were $5.6 \pm 0.19 \%$, and it decreased to $4.9 \pm 0.16 \%$ with treatment $(\mathrm{P}<.001$; Table 4$)$.

\begin{tabular}{|l|l|l|}
\hline Vitamin B12 deficiency anemia & Before treatment (mean HbA1c \pm SD) & After treatment (mean HbA1c \pm SD) \\
\hline Group 1 & $5.9 \pm 0.3$ & $5.0 \pm 0.15$ \\
\hline Group 2 & $5.6 \pm 0.19$ & $4.9 \pm 0.16$
\end{tabular}

TABLE 4: Mean HbA1c concentrations in mild and moderate vitamin B12 deficiency anemia groups before and after treatment

Abbreviations: HbA1c, glycated haemoglobin; SD, standard deviation. 


\section{Cureus}

\begin{tabular}{|l|l|l|}
\hline Nutritional anemia types & Group 1 & Group 2 \\
\hline Iron deficiency anemia & $6.1 \pm 0.23$ & $5.5 \pm 0.24$ \\
\hline Vitamin B12 deficiency anemia & $5.9 \pm 0.3$ & $5.6 \pm 0.19<.001$ \\
\hline
\end{tabular}

TABLE 5: The difference of HbA1c (\%) values before and after treatment in group one versus group two of both types of anemia

Abbreviation: HbA1c, glycated haemoglobin.

\section{Discussion}

We considered nutritional anemia's effects on HbA1c, with a particular focus on iron and vitamin B12 deficiency anemia. We found that there was a significant decrease in HbA1c in both groups of iron deficiency patients after treatment. Similar results were obtained in the studies done by Coban et al. [13], Ford et al. [14], and El-Agouza et al. [15]. We found that HbA1c values were higher for patients with severe anemia when compared with patients with mild and moderate anemia. A study by Silva et al. obtained similar results [16].

Our findings contradicted those reported by Sinha et al., who reported a subsequent rise in HbA1c with iron supplementation (4.6\% to $5.9 \%$ ) in 50 iron deficiency anemia patients and 50 controls [2]. Similar contradictory results were also reported by Van Heyningen et al. [17].

The vitamin B12-deficiency anemia patients showed a significant decrease in HbA1c with treatment for anemia. Very few studies in the literature analyzed the relationship between B12 deficiency and HbA1c. Gram-Hansen et al. conducted a study that included both iron $(n=10)$ and B12 $(n=10)$ deficiency anemia patients [18]. They reported no significant differences in HbA1c concentrations in iron-deficient patients, vitamin B12 deficient patients, and controls. The study conducted by Capoor et al. [19] had results similar to our study. We found that HbA1c was higher in the vitamin B12 deficiency anemia subjects with severe anemia when compared with mild and moderate anemia subjects. According to Pani et al. [20] and Kilpatrick et al. [21], the age of the individuals also plays a vital role in the HbA1c of the individuals. In their study, $\mathrm{HbA1c}$ increased with the age of the individuals. We found that HbA1c concentrations did not always change with the degree of anemia. Table 6 gives a brief view regarding the results of some studies on HbA1c in anemia $[2,13,16-18]$.

Studies showing a decrease in $\mathrm{HbA1c}$ levels with the treatment of anemia

Coban et al. [13]

Silva et al. [16]
Studies showing no change in HbA1c levels

Heyningen et al. [17]

Gram-Hansen et al. [18]
Studies showing an increase in $\mathrm{HbA1c}$ levels with the treatment of anemia

Sinha et al. [2]

\section{TABLE 6: Select studies regarding HbA1c in anemia based on their results}

Abbreviation: HbA1c, glycated haemoglobin.

\section{Limitations}

A more extensive multicentric epidemiological study is needed to highlight the generalized burden (i.e., the effect of anemia on HbA1c levels in individuals without diabetes). As the present study was hospital-based, our findings should not be generalized to the whole population. Other factors that alter HbA1c values in a general population should also be considered.

\section{Conclusions}

HbA1c in both types of anemia subjects showed a significant reduction with appropriate anemia therapy. The considerable variations in $\mathrm{HbA} 1 \mathrm{c}$ in anemia patients might contribute to inaccurate diabetes status classification of these subjects. There is an observable, albeit limited, inverse relationship between rising $\mathrm{Hb}$ levels and falling HbA1c levels in patients with anemia. Hence anemia should be treated before using HbA1c as a diagnostic tool for diabetes. Physicians should consider confirming Hb values before determining the glycemic status of anemic patients as this coexistence may lead to misinterpretation of diabetes status. 


\section{Additional Information \\ Disclosures}

Human subjects: Consent was obtained by all participants in this study. Maharajah Institute of Medical Sciences issued approval MIMS/IEC - 11/2017. Animal subjects: All authors have confirmed that this study did not involve animal subjects or tissue. Conflicts of interest: In compliance with the ICMJE uniform disclosure form, all authors declare the following: Payment/services info: All authors have declared that no financial support was received from any organization for the submitted work. Financial relationships: All authors have declared that they have no financial relationships at present or within the previous three years with any organizations that might have an interest in the submitted work. Other relationships: All authors have declared that there are no other relationships or activities that could appear to have influenced the submitted work.

\section{References}

1. Gupta S, Jain U, Chauhan N: Laboratory diagnosis of HbA1c: a review . J Nanomed Res. 2017, 5:00120. 10.15406/jnmr.2017.05.00120

2. Sinha N, Mishra TK, Singh T, Gupta N: Effect of iron deficiency anemia on hemoglobin A1c levels . Ann Lab Med. 2012, 32:17-22. 10.3343/alm.2012.32.1.17

3. Sacks DB, Arnold M, Bakris GL, et al.: Guidelines and recommendations for laboratory analysis in the diagnosis and management of diabetes mellitus. Clin Chem. 2011, 57:1-47. 10.1373/clinchem.2010.161596

4. Camargo JL, Gross JL: Conditions associated with very low values of glycohemoglobin are measured by an HPLC method. J Clin Pathol. 2004, 57:346-349. 10.1136/jcp.2002.007088

5. Radin MS: Pitfalls in hemoglobin A1c measurement: when results may be misleading . J Gen Intern Med. 2014, 29:388-394. 10.1007/s11606-013-2595-x

6. Arnold JG, McGowan HJ: Delay in diagnosis of diabetes mellitus due to inaccurate use of hemoglobin A1C levels. J Am Board Fam Med. 2007, 20:93-96. 10.3122/jabfm.2007.01.060086

7. When is hemoglobin A1c inaccurate in assessing glycemic control? . (2012). Accessed: January 3, 2018: http://www.clinicalcorrelations.org/?p=5190.

8. Pharmacologic approaches to glycemic treatment: standards of medical care in diabetes . (2018). Accessed: January 3, 2019: https://care.diabetesjournals.org/content/41/Supplement_1/S73.

9. Nitin S: HbA1c and factors other than diabetes mellitus affecting it. Singapore Med J. 2010, 51:616-22.

10. Randie R. Little, Curt L. Rohlfing, Alethea L. Tennill, et al.: Measurement of HbA1c in patients with chronic renal failure. Clin Chim Acta. 2013, 418:73-76. 10.1016/j.cca.2012.12.022

11. Ram VS, Kumar G, Kumar M, Verma VK, Kela D, Ali K: Association of subclinical hypothyroidism and HbA1c levels in non-diabetic subjects attending rural tertiary care centre in central India. Int J Res Med Sci. 2017, 5:3345-3349. 10.18203/2320-6012.ijrms20173097

12. World Health Organization: Haemoglobin concentrations for the diagnosis of anaemia and assessment of severity. (2011). Accessed: October 3, 2020: http://www.who.int/vmnis/indicators/haemoglobin.pdf.

13. Coban E, Ozdogan M, Timuragaoglu A: Effect of iron deficiency anemia on the levels of hemoglobin A1c in nondiabetic patients. Acta Haematol. 2004, 112:126-128. 10.1159/000079722

14. Ford ES, Cowie CC, Li C, Handelsman Y, Bloomgarden ZT: Iron-deficiency anemia, non-iron-deficiency anemia, and HbA1c among adults in the US. J Diabetes. 2011, 3:67-73. 10.1111/j.1753-0407.2010.00100.x

15. El-Agouza I, Abu Shahla A, Sirdah M: The effect of iron deficiency anemia on the levels of hemoglobin subtypes: possible consequences for clinical diagnosis. Clin Lab Haematol. 2002, 24:285-289. 10.1046/j.1365-2257.2002.00464.x

16. Silva JF, Pimentel AL, Camargo JL: The effect of iron deficiency anemia on HbA1c levels is dependent on the degree of anemia. Clin Biochem. 2016, 49:117-120. 10.1016/j.clinbiochem.2015.09.004

17. Van Heyningen C, Dalton RG: Glycosylated hemoglobin in iron-deficiency anemia . Lancet. 1985, 1:874. 10.1016/s0140-6736(85)92234-2

18. Gram-Hansen P, Eriksen J, Mourits-Andersen T, Olesen L: Glycosylated hemoglobin (HbA1c) in iron- and vitamin B12 deficiency. J Intern Med. 1990, 227:133-136. 10.1111/j.1365-2796.1990.tb00131.x

19. Capoor DS, Chaturvedi DS, Manglunia DA, Singla DA, Gupta DA, Sharma DK: Impact of iron and vitamin B12 anemia at glycosylated hemoglobin level: a case-control study. IOSR-JDMS. 2017, 16:01-04. 10.9790/08531601120104

20. Pani LN, Korenda L, Meigs JB, et al.: Effect of aging on A1C levels in individuals without diabetes: evidence from the Framingham Offspring Study and the National Health and Nutrition Examination Survey 20012004. Diabetes Care. 2008, 31:1991-1996. 10.2337/dc08-0577

21. Kilpatrick ES, Dominiczak MH, Small M: The effects of aging on glycation and the interpretation of glycaemic control in Type 2 diabetes. QJM. 1996, 89:307-312. 10.1093/qjmed/89.4.307 